\title{
Child Location Tracker with Virtual Fence
}

\author{
Joseph Dedy Irawan ${ }^{1, *}$,Emmalia Adriantantri ${ }^{2}$, and Agustinus Bohaswara Haryasena ${ }^{1}$ \\ ${ }^{1}$ Informatics, National Institute of Technology, Raya Karanglo Km.2 Malang 65153, \\ East Java, Indonesia \\ ${ }^{2}$ Industrial Engineering, National Institute of Technology, Raya Karanglo Km.2 Malang 65153, \\ East Java, 65153 Indonesia
}

\begin{abstract}
With widespread news of child abductions circulating in the media, child abduction is one of the anxieties felt by parents, especially those who have small children. Many ways have been tried to overcome this risk, ranging from restricting children from leaving the home alone to schools building fences around the school so students cannot leave the school grounds and not giving people the opportunity to enter a school without a clear purpose. With the development of information technology and the increasing availability of communication devices, such as the smartphones that are owned by so many children, these devices can be used to track the whereabouts of children so they can be easily monitored by their parents wherever they may be. By adding an application to the device, a boundary area can be made within which a child can safely be active, such as the school grounds. After children enter the school area in possession of this application, a message will automatically be sent to parents and teachers if the child and the device unexpectedly leave the school area so immediate action can be taken.
\end{abstract}

Keywords: Alert system, child kidnapping prevention, child location monitoring, global positioning system monitoring, safety of children.

\section{Introduction}

With the increasingly widespread crime rate involving children, child abduction is one of the anxieties felt by parents today, especially those who have small children. Many methods have been attempted to overcome this pernicious crime, ranging from restricting children from leaving the house alone and schools building a fence around their grounds to prevent students from leaving the school environment to not giving people the opportunity to enter a school without a clear purpose. But no method has been able to guarantee the safety of children, with gaps still existing for criminals to carry out their nefarious actions.

Thus, to improve children's safety and to calm their parents, a method required to help look after children by using an easy and common tool. One such tool that is already widely used is a device that will send location information if the device is pressed [1-3]. However, for this equipment to work, someone still has to press a button. Meanwhile, the installation of a CCTV camera in a public location that can be rotated and has automatic tracking [4] will reduce the number of crimes. When such a camera is in use, the perpetrators of a crime

\footnotetext{
* Corresponding author: joseph@ lecturer.itn.ac.id
} 
can be known and can be traced. In this research, a safety system will be described that uses an Android device which is no longer a rare device for children to have, whereby the system will automatically inform parents and teachers if the child leaves the school area.

The purpose of this study was to create a proposed alert system for the device, which is a virtual fence that can be constructed for the children wherever they do their activities for example the school area or the playground. By working within the application to create a virtual fence, parents, teachers and school officials will automatically be given a warning message through the app when the child steps (or is carried) outside the school area or playground. Once the alert is sent out, action can be taken immediately to retrieve the child from the area outside their normal boundaries.

\section{Materials and methodology}

\subsection{Global positioning system (GPS)}

A GPS device is a navigation device that works based on signals from satellites, where it shows the geographic location of the device. A number of GPS satellites revolve around the earth while sending signals to the earth, which can be received by GPS devices. Determining the user's location is done using the triangulation method shown in Figure 1.

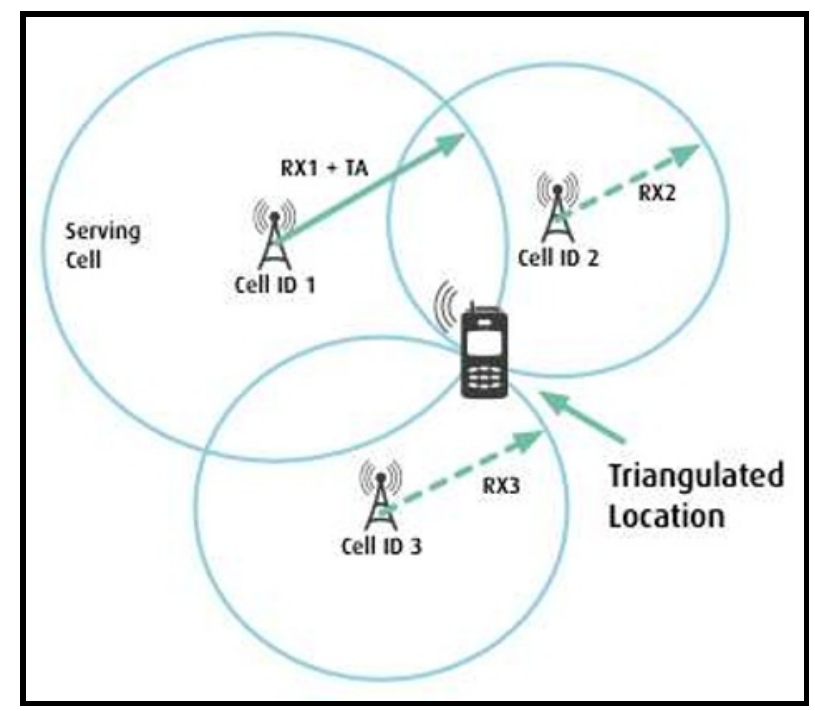

Fig. 1. Triangulation to determine a user's location [1].

In the process of triangulation, the position can be calculated in two dimensions or three dimensions. To find the position in three dimensions requires three satellites, whereas determining the position in three dimensions requires four GPS channels. In two dimensions, the values obtained are the latitude and longitude coordinates. In three dimensions, the data obtained are the values of latitude, longitude and altitude. After fixing the location, GPS can also be used to calculate distance, speed and distance travelled. 


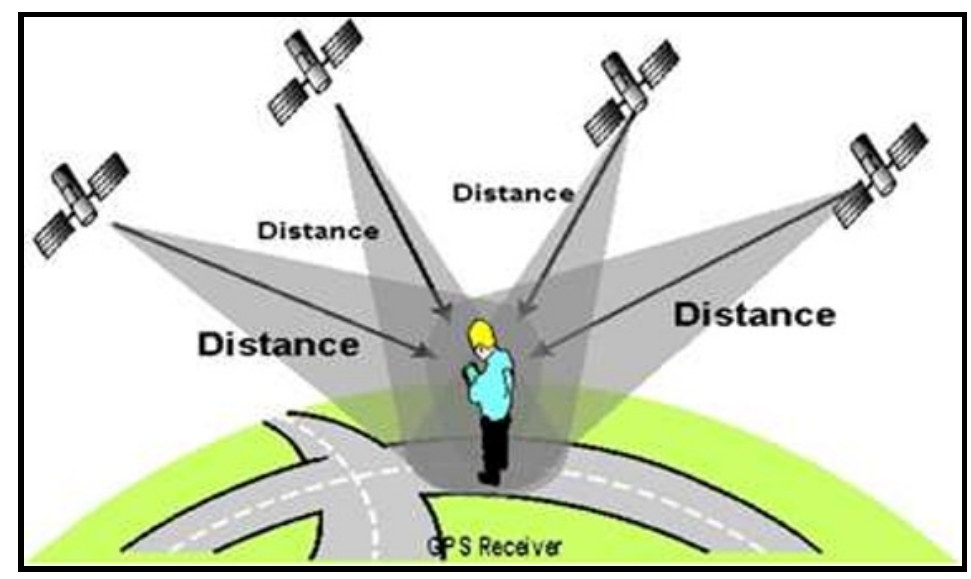

Fig. 2. Determining the position in three dimensions [1].

\section{2 loT and location tracking}

With the advances in computer and internet network technology, it is possible for us to connect other equipment to the internet, so that the equipment can be monitored and controlled remotely $[5,6]$. This process of internet-based remote control is now better known as the Internet of Things (IoT), meaning a process that utilizes electronic equipment connected to an internet network [7].

The most common location tracking method is to use a mobile device [8] equipped with a GPS receiver so that it can know its location and with Wi-Fi and Bluetooth connections that can be used for communication with other equipment. By using the smartphone, the location of a person can be known [9, 10], so that this can be used to monitor the whereabouts of children.

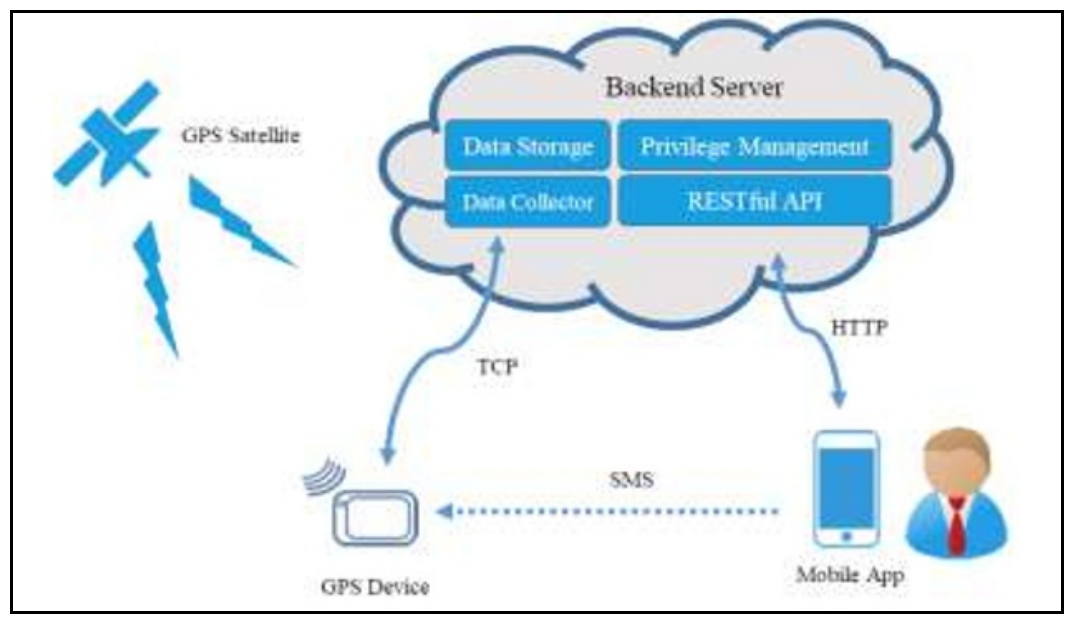

Fig. 3. Location tracking using the Mobile Application [10].

\subsection{Virtual fencing}

Virtual fencing in this research is done by determining certain areas that children can access, such as school areas, playground areas and other school areas, so that the location of 
the child can be monitored. The predetermined area that the child should stay within is determined not using a diameter but using a vertex boundary area so that a more accurate virtual fence is obtained.

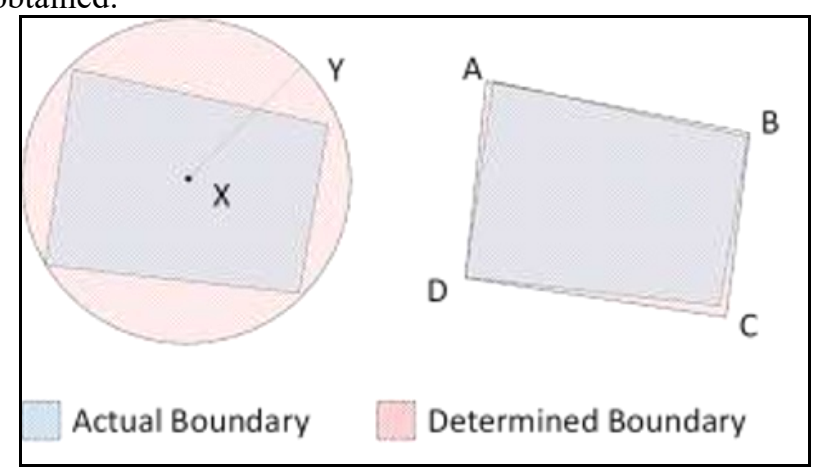

Fig. 4. Area differences based on radius and area based on application.

\subsection{Flowchart}

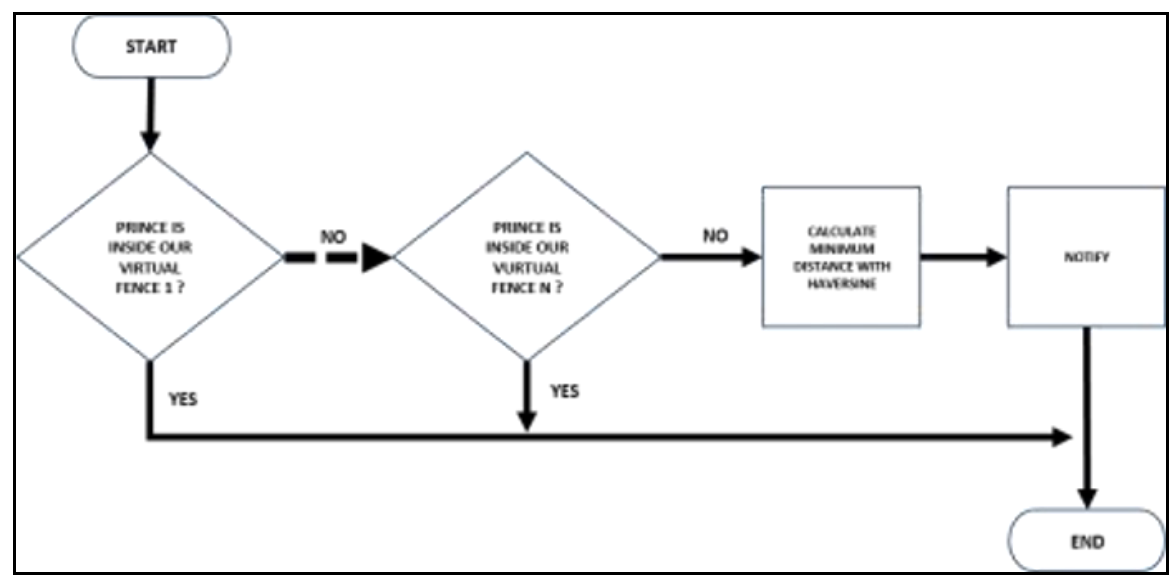

Fig. 5. System flowchart.

Figure 5 is a flowchart to determine the distance and whereabouts of children. The notification system is created using FCM (Firebase Cloud Messaging) in this way:

i. First, determine whether the child is in a predetermined location. This is calculated by finding the relativity of the point of existence of children formed from longitude and latitude with the boundary area specified by the parent. If yes, the application will give a green indicator.

ii. Second, in the same way, determine whether the child is in another registered location, such as a playground.

iii. If not, the application will calculate the minimum distance between the location of the child and the nearest Location Path where the child is registered and then the application will notify the parents with a red alert code.

\section{Implementation and results}

Both parent and child can see the details of Saved Location, which is a row of coordinates for the Virtual-Fence or Location-Path, a description of the place where the child should be 
at. Parents can create a new Saved Location with their Location Path (see Figure 6). Parents can also add a limiting point or Location Path consisting of at least four and a maximum of eight corner points.

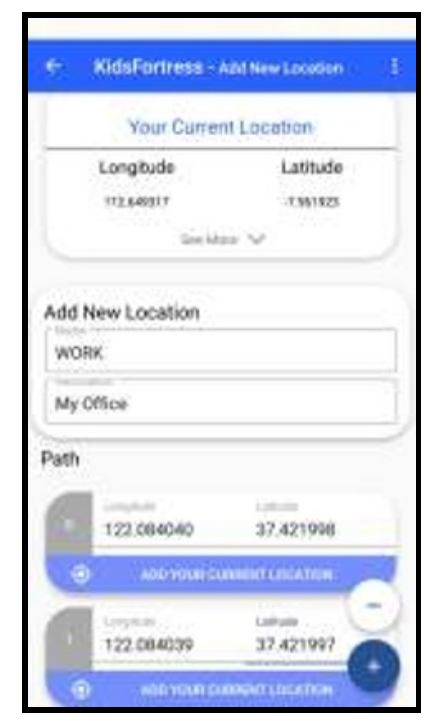

Fig. 6. Virtual fence setting.

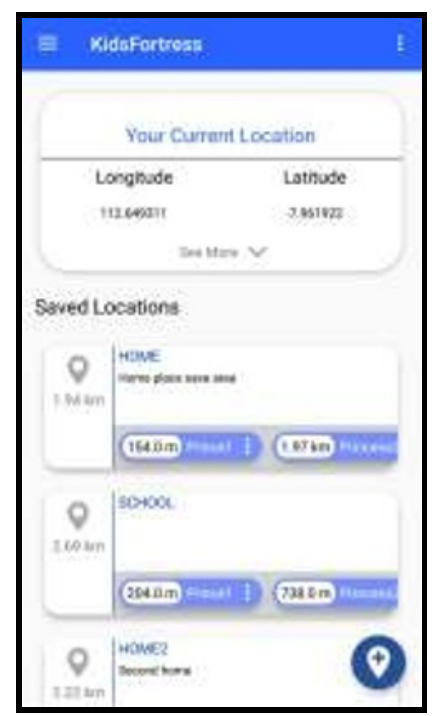

Fig. 7. Monitoring a child's location.

Setting the virtual fence:

i. Parents register or $\log$ in to the application with a central database in the form of Google's Firebase real-time database for app building.

ii. The parent will add the child and then wait for the child to be confirmed. If the child is rejected, the application will give a notification to the parent.

iii. After being confirmed that the child is accepted by the system, the parent can determine that the child has been registered in the Saved Location that is often occupied by the child. 
iv. Parents can add or create a secure location or Saved Location by determining the Location Path or the limiting points for determining safe areas. For example, the school area can consist of four points formed by longitude and latitude representing the edges of the school boundary fence.

v. Parents can already monitor their child's location, through distance indicators and by seeing if the child is still in a safe area. Also, vital information such as last time online, battery state, and smartphone information can be monitored.

vi. What the child should do is to register or log in to the customized application and adjust it to the central database and receive the confirmation sent by parents. After confirming, the child can see the parent information and the safe locations.

vii. The application will automatically send the current location and vital information, such as battery state and other information, through Firebase.

\section{Conclusion}

GPS accuracy is about $3 \mathrm{~m}$ to $5 \mathrm{~m}$, causing inaccurate distance, a determination that can be overcome with software. The proposed system is more accurate than the radius point of location determination. Overall, the system is working, and the parents are less worried about their most loved ones.

\section{References}

1. R. Velayutham, M. Sabari, M.S. Rajeswari. An innovative approach for women and children's security-based location tracking system. Paper Presented in International Conference on Circuit, Power and Computing Technologies (ICCPCT) (Kumaracoil, India, 2016). IEEE, 1252-1257(2016). https://ieeexplore.ieee.org/abstract/document/7530325

2. S.C. Mukhopadhyay. IEEE sensors journal, 15,3:1321-1330(2014). https://ieeexplore.ieee.org/document/6974987

3. B. Abinaya, S. Gurupriya, M. Pooja. Iot based smart and adaptive lighting in street lights. Paper Presented in 2nd International Conference on Computing and Communications Technologies (ICCCT) (Chennai, India, 2017). IEEE, 195198(2017). https://ieeexplore.ieee.org/document/7972267

4. Y. Fujii, N. Yoshiura, N. Ohta, A. Takita, H. Ueda, K. Maru. Journal of Community Informatics, 12,1:152-156(2016).

http://www.ci-journal.net/index.php/ciej/article/view/1271

5. S. Saha, S. Chatterjee, A.K. Gupta, I. Bhattacharya, T. Mondal. TrackMe - a low power location tracking system using smart phone sensors. Paper Presented in International Conference on Computing and Network Communications (CoCoNet) (Kerala, India, 2015). IEEE, 457-464(2015).

https://ieeexplore.ieee.org/document/7411226

6. M.P. Fanti, M. Roccotelli, J.J. Lesage, G. Faraut. Motion detector placement optimization in smart homes for inhabitant location tracking. Paper Presented in 21st International Conference on Emerging Technologies and Factory Automation (ETFA) (Berlin, Germany, 2016). IEEE, 1-6(2016).

https://ieeexplore.ieee.org/document/7733558

7. G. Suthokumar, J. Tharmakulasingam, A. Johnnirajh, P. Subendran, D. Dias. Smart building-Towards the insight remotely. Paper Presented in International Conference on the Internet of Things and Applications (IOTA) (Pune, India, 2016). IEEE, 395400(2016). https://ieeexplore.ieee.org/document/7562759 
8. H. Tang, J. Shi, K. Lei. A smart low-consumption IoT framework for location tracking and its real application. Paper Presented in 6th International Conference on Electronics Information and Emergency Communication (ICEIEC) (Beijing, China, 2016). IEEE, 306-309(2016). https://ieeexplore.ieee.org/document/7589744

9. S. Chandrasekaran, N.U. Maheswari. Overview on location tracking for authentication using smartphones. Paper Presented in 10th International Conference on Intelligent Systems and Control (ISCO) (Tamilnadu, India, 2016). IEEE, 16(2016). https://ieeexplore.ieee.org/document/7726919

10. J.J. Pan, S.J. Pan, J. Yin, L.M. Ni, Q. Yang. IEEE transactions on pattern analysis and machine intelligence, 34,3:587-600(2011).

https://ieeexplore.ieee.org/document/5989824 